\begin{tabular}{|c|l|}
\hline Title & $\begin{array}{l}\text { Double Beam Photoacoustic Spectroscopic Studies on Transient A bsorption of Titanium(IV) Oxide Photocatalyst } \\
\text { Powders }\end{array}$ \\
\hline Author(s) & Murakami, Naoya; Prieto Mahaney, Orlando Omar; A be, Ryu; Torimoto, Tsukasa; Ohtani, Bunsho \\
\hline Citation & $\begin{array}{l}\text { Journal of Physical Chemistry C, 111(32), 11927-11935 } \\
\text { https://doi.org/10.1021/j071362x }\end{array}$ \\
\hline Issue Date & 2007 \\
\hline Doc URL & http://hdl.handle.net/2115/48669 \\
\hline Type & article \\
\hline File Information & JPhysChemC2007_11927.pdf \\
\hline
\end{tabular}

Instructions for use 


\title{
Double-Beam Photoacoustic Spectroscopic Studies on Transient Absorption of Titanium(IV) Oxide Photocatalyst Powders
}

\author{
Naoya Murakami, ${ }^{\dagger}$ Orlando Omar Prieto Mahaney, ${ }^{\dagger}$ Ryu Abe, ${ }^{\dagger, \$}$ Tsukasa Torimoto, ${ }^{\dagger, t, \S}$ and \\ Bunsho Ohtani*,,, \\ Graduate School of Environmental Earth Science, Hokkaido University, Sapporo 060-0810, Japan, and \\ Catalysis Research Center, Hokkaido University, Sapporo 001-0021, Japan
}

Received: February 17, 2007; In Final Form: May 29, 2007

\begin{abstract}
In situ photoabsorption properties of titanium(IV) oxide $\left(\mathrm{TiO}_{2}\right)$ powders under continuous ultraviolet irradiation were investigated by double-beam photoacoustic (PA) spectroscopy. This PA measurement enabled observation of two kinds of ultraviolet-light-induced intermediate species appearing on various kinds of $\mathrm{TiO}_{2}$ powder samples. Most of the samples (type 1) exhibited photoabsorption due to the production of trivalent titanium $\left(\mathrm{Ti}^{3+}\right)$ species, while transient absorption assigned to trapped holes or surface peroxy species was also observed for anatase samples with a relatively large specific surface area (type 2). Time-resolved measurements and analyses of the kinetics of photoinduced $\mathrm{Ti}^{3+}$ species suggest that electrons accumulated in type- 2 samples have high reactivity toward molecular oxygen compared to type-1 samples. Saturation limits of intensity of the PA signal attributed to $\mathrm{Ti}^{3+}$ species under deaerated conditions in the presence of surface-adsorbed methanol were estimated for both types of samples, and their linear relation with density of $\mathrm{Ti}^{3+}$ species estimated by a conventional photochemical technique was observed. This suggests that the present double-beam PA technique is an alternative feasible method for estimation of density of $\mathrm{Ti}^{3+}$ species, which is a potential measure of density of crystalline defects.
\end{abstract}

\section{Introduction}

Titanium(IV) oxide $\left(\mathrm{TiO}_{2}\right)$ has been one of the most attractive materials as a photocatalyst, owing to its nontoxicity, availability, superior redox ability, and photostability., ${ }^{1,2}$ Photocatalytic reactions on such semiconducting materials are induced by photoexcited electrons and positive holes, which are generated by above-band gap irradiation. These species move around in the bulk and react with adsorbates on the surface, i.e., they induce photocatalytic redox reactions. However, a large proportion of them is stabilized at deep trapping states or undergoes recombination with each other without being used in chemical reactions. Therefore, photocatalytic activity, i.e., reaction rate, must be a function of, at least, both reactivity of electrons and holes with substrates and probability of the recombination. The former may be governed by the amount of adsorbed substrates assuming that the same number of electron-hole pairs is generated regardless of the kind of photocatalyst under irradiation. The amount of adsorbed substrates must be closely related to the surface area of photocatalyst particles, and this is the reason why smaller-sized particles, i.e., particles with larger specific surface area, sometimes show higher photocatalytic activity.

On the other hand, the importance of the latter factor, recombination, had been pointed out earlier, but few studies have extracted the effect of recombination from the apparent overall photocatalytic reaction rate, because recombination does

* Corresponding author. Fax: +81-11-706-9133. E-mail: ohtani@ cat.hokudai.ac.jp.

$\dagger$ Graduate School of Environmental Earth Science.

$\doteqdot$ Catalysis Research Center.

$\S$ Present address: Department of Crystalline Materials Science, Graduate School of Engineering, Nagoya University, Chikusa-ku, Nagoya 464-8603, Japan. not give any products to be detected and thus is not detected directly. As an example of direct measurements of the recombination process, pump-probe transient photoabsorption measurements using femtosecond laser systems have been performed and have revealed that decay of photoabsorption of trapped electrons by recombination with holes can be reproduced by a second-order rate equation and the estimated rate constant of recombination depends on the nature of $\mathrm{TiO}_{2}$ powder. ${ }^{3}$ It is presumed that the recombination rate constant is determined by the density of recombination sites, though the constant cannot be applied to a rate expression for photocatalytic reactions operated under conventional continuous photoirradiation where the recombination may proceed through first-order kinetics due to much lower density of electron-hole pairs in each particle.

The most probable candidate of the recombination center is localized electronic states in the photocatalyst that originate in crystal defects and impurities. However, there are no methods for direct measurement of the defect density in intact powder samples, whereas various evaluation methods have been established on defect properties in films and crystal surfaces. ${ }^{4} \mathrm{We}$ have developed a method to measure the density and energy level of photochemically produced trivalent titanium $\left(\mathrm{Ti}^{3+}\right)$ species in $\mathrm{TiO}_{2}$ powders suspended in a deaerated aqueous solution containing an electron donor, such as methanol. ${ }^{5} \mathrm{~A}$ possible mechanism of $\mathrm{Ti}^{3+}$ formation is trapping of electrons by a five-coordinate titanium ion with an oxygen vacancy, which is a well-known dopant of an n-type metal oxide semiconductor. Judging from its almost liner relation with the above-mentioned recombination rate constant, $\mathrm{Ti}^{3+}$ density is a measure of the defect density. ${ }^{5}$ Although these species are not identical, $\mathrm{Ti}^{3+}$ density can be an empirical measure of recombination rate in $\mathrm{TiO}_{2}$ photocatalysts, and this can be used as important parameter 
as well as specific surface area when photocatalytic activities are discussed.

Properties of photochemically produced $\mathrm{Ti}^{3+}$ in $\mathrm{TiO}_{2}$ powders have also been measured by electron spin resonance (ESR) ${ }^{6-12}$ and diffuse reflectance infrared Fourier transform spectroscopy (DRIFTS). ${ }^{13,14}$ Most of these measurements require pretreatments or special conditions, such as high vacuum or low temperature, which is far from ordinary conditions for photocatalytic reactions. Electronic absorption spectroscopy is an alternative method, and an improvement of time-resolved resolution with ultrafast spectroscopy enabled investigation of the dynamics of excited species in a time scale of pico- to microseconds. ${ }^{15-20}$ In these studies, diffuse reflectance spectroscopy (DRS) has been often employed to estimate absorption of powder samples. However, scattering and reflection sometimes cause difficulty in accurate measurement of photoabsorption. ${ }^{21}$

Photoacoustic spectroscopy (PAS), ${ }^{22,23}$ one of the photothermal spectroscopic techniques, is applicable to even opaque and strongly scattering solid materials, because photoabsorption is detected by photothermal waves, i.e., acoustic sounds generated by relaxation of the photoexcited state, e.g., recombination of an electron-hole pair in a semiconductor photocatalyst. Moreover, photoacoustic (PA) detection is more sensitive than conventional optical methods, and even small absorption such as that due to a small number of defects can be detected. Several papers on PAS have reported the results for a few $\mathrm{TiO}_{2}$ powders. ${ }^{24-26}$ Recently, we proposed a method of $\mathrm{Ti}^{3+}$ density evaluation for $\mathrm{TiO}_{2}$ powders using double-beam (DB) PAS. ${ }^{27}$ This enables us to measure in situ absorption spectra under ultraviolet (UV) irradiation, which is not possible by conventional techniques. DB-PAS has been used to investigate photochromism of $\mathrm{TiO}_{2}$ powders ${ }^{28}$ and transient absorption of dye adsorbed on zinc oxide, ${ }^{29}$ but no systematic studies for photocatalyst powders have so far been performed. In the present study, we investigated the photoinduced $\mathrm{Ti}^{3+}$ and trapped holes or surface peroxy species by controlling the atmosphere (oxygen and/or hole scavenger). The kinetics of photoinduced $\mathrm{Ti}^{3+}$ formation is discussed on the basis of results of time-course measurement.

\section{Experimental Section}

2.1. Materials. Twenty-two $\mathrm{TiO}_{2}$ powder samples from commercial sources (Merck, Ishihara CR-EL, Hombikat UV100, Wako amorphous, Degussa P25, and Showa Titanium ST series) and reference catalysts supplied by the Catalysis Society of Japan (JRC-TIO series) were used. In addition to these intact samples, samples with three kinds of treatment were also used for this study. Hydrogen peroxide $\left(\mathrm{H}_{2} \mathrm{O}_{2}\right)$ treatment was carried out by stirring a suspension of $\mathrm{TiO}_{2}$ powder in an aqueous $\mathrm{H}_{2} \mathrm{O}_{2}$ solution. Platinum-deposited samples $\left(\mathrm{Pt} / \mathrm{TiO}_{2}\right)$ were obtained by photodeposition as follows: an aqueous solution containing $\mathrm{TiO}_{2}$ powders and methanol (50 vol \%), and hexachloroplatinic acid $\left(\mathrm{H}_{2} \mathrm{PtCl}_{6} \cdot 6 \mathrm{H}_{2} \mathrm{O}\right)$, the amount of which corresponds to 0.01 wt \% loading of platinum $(\mathrm{Pt})$, was photoirradiated under an argon atmosphere with magnetic stirring. $\mathrm{TiO}_{2}$ powders with adsorbed iron(III) ion $\left(\mathrm{Fe}^{3+}\right)$ were obtained by stirring a mixture of $\mathrm{TiO}_{2}$ powders and an aqueous iron(III) sulfate $\left(\mathrm{Fe}_{2}\left(\mathrm{SO}_{4}\right)_{3}\right)$ solution.

2.2. Characterization of Photocatalysts. The crystal structures of $\mathrm{TiO}_{2}$ samples were determined by X-ray diffraction (XRD; Rigaku RINT2000) analysis and primary particle size (PPS) was estimated by Scherrer's equation using corrected halfheight width of the most intense peaks of anatase and rutile.
Specific surface area $\left(S_{\mathrm{BET}}\right)$ was measured by nitrogen adsorption on the basis of the Brunauer-Emmett-Teller equation using a NOVA 1200e analyzer (Yuasa Ionics). Secondary particle size (SPS) was estimated by a laser diffraction particle analyzer (Shimadzu SALD-7000). Diffuse reflectance spectra were recorded using a photonic multichannel analyzer (Hamamatsu Photonics PMA-11 C7473-36). The density of $\mathrm{Ti}^{3+}$ was measured by photoinduced electron accumulation in $\mathrm{TiO}_{2}$ suspended in deaerated aqueous solutions containing sacrificial hole scavengers and subsequent reduction of methylviologen to its cation radical, according to the literature. ${ }^{5}$

2.3 Photoacoustic Spectroscopy. Two types of PA cells, a standard-type cell (inner volume, ca. $0.5 \mathrm{~cm}^{3}$ ) and a gasexchangeable cell (inner volume, ca. $1 \mathrm{~cm}^{3}$ ) equipped with two valves for gas flow, were used. Each cell was composed of an aluminum body and a Pyrex glass window, being transparent over the range of measurements, 300-600 nm. These cells were suspended with rubber bands to minimize vibrational noise during the measurement. A powder sample was placed in the cell. The atmosphere was ambient air (amb-air) or controlled by a gas flow of argon $(\mathrm{Ar})$, nitrogen $\left(\mathrm{N}_{2}\right)$, oxygen $\left(\mathrm{O}_{2}\right)$, and artificial air (art-air). The difference between amb-air and artair is the content of water vapor; the former contains a large amount of water vapor, whereas the amount in the latter is negligible. The measurements were conducted in a closed system at room temperature. Monochromatic light (ca. $0.2 \mathrm{~mW} \mathrm{~cm}^{-2}$ ) was extracted from the output of a $300 \mathrm{~W}$ Xe lamp (Eagle LX300) using a monochromator (Jasco CT-101T) and modulated by a light chopper at $80 \mathrm{~Hz}$. The wavelength of monochromatic light was scanned from 600 to $300 \mathrm{~nm}$ at $5 \mathrm{~nm}$ steps. The PA signal acquired by a condenser microphone buried in the cell was amplified and monitored by a digital lock-in amplifier (NF LI5640). In addition to this ordinary single-beam (SB) measurement, measurements with simultaneous continuous photoirradiation, i.e., DB measurements, were also carried out. A more intense light beam from another Xe lamp passing through a UV-D33S optical filter (transmitting radiation of ca. 300-400 nm, Asahi Techno Glass) was used as a continuous UV-light source $\left(8.2 \mathrm{~mW} \mathrm{~cm}^{-2}\right)$. The PA signal was normalized using carbon black powder (Nilaco) as a reference to compensate wavelength-dependent light intensity.

2.4. Time-Resolved Photoacoustic Analysis. Three types of light-emitting diodes (LEDs) emitting light at 455, 530, and $625 \mathrm{~nm}$ (Luxeon LXHL-NRR8, NM98, and ND98) were used as probe lights, and their output intensity was modulated by a digital function generator (NF DF1905) at $80 \mathrm{~Hz}$. In addition to the modulated light, a UV-LED (Nichia NCCU033, emitting light at $365 \mathrm{~nm}$ ) was also used as a simultaneous continuous irradiation $\left(2.8 \mathrm{~mW} \mathrm{~cm}{ }^{-2}\right)$ for excitation of $\mathrm{TiO}_{2}$. The atmosphere was controlled by a flow of $\mathrm{Ar}$ or $\mathrm{O}_{2}$ containing methanol vapor $\left(\mathrm{Ar}+\mathrm{CH}_{3} \mathrm{OH}, \mathrm{O}_{2}+\mathrm{CH}_{3} \mathrm{OH}\right)$, and the measurements were conducted after shutting off the valves, i.e., in the closed system at room temperature.

\section{Results and Discussion}

3.1. SB Measurements. Figure 1a shows SB-PA spectra of typical samples measured in amb-air. For most of the samples (type-1 samples as described later) under these measurement conditions when the irradiation light intensity was low, repeated SB measurements did not cause any notable change in the spectra, even though the probe light was absorbed by $\mathrm{TiO}_{2}$ samples at less than ca. $400 \mathrm{~nm}$. The detected PA signal corresponds to generation of heat as a result of relaxation of photoexcited states, e.g., recombination of electron-holes in 

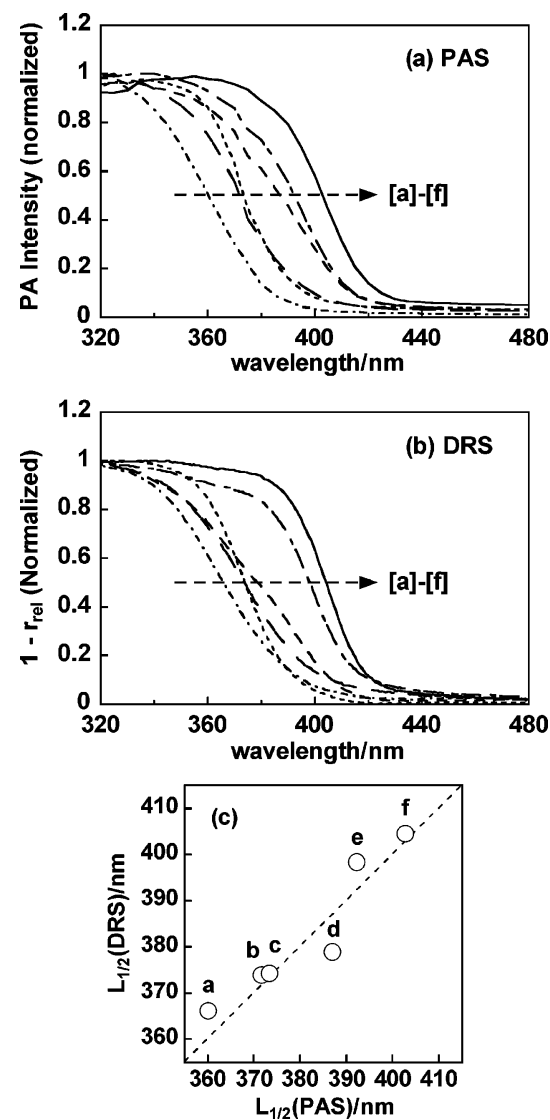

Figure 1. (a) SB-PA and (b) DR spectra normalized at maximum value of (curve a) Wako \{amorphous\}, (curve b) JRC-TIO-12 \{A\}, (curve c) Merck $\{A\}$, (curve d) Degussa P25 \{A/R $\}$, (curve e) JRC-TIO-6 $\{R\}$, and (curve f) CR-EL $\{R / A\}$. $A$ and $R$ in braces denote the predominant crystal phase, anatase or rutile. Measurements were performed in the amb-air. (c) Relation between $L_{1 / 2}$ for PAS and for DRS.

the above-band gap wavelength region. Since photoluminescence from photoexcited pristine $\mathrm{TiO}_{2}$ is negligible at ambient temperature and chemical reaction by excited electrons and positive holes might be slow and independent of wavelength, the heat generated by their recombination is presumed to be proportional to photoabsorption.

Figure 1b shows diffuse reflectance spectra of $\mathrm{TiO}_{2}$ samples in the same wavelength region. Absorption $\left(1-r_{\text {rel }}\right.$, where $r_{\text {rel }}$ is reflection of the sample relative to that of barium sulfate $\left(\mathrm{BaSO}_{4}\right)$ standard) was plotted in this figure. It is reasonable to find resemblance of these two sets of spectra since both PA and DR spectra correspond to wavelength dependence of photoabsorption of samples. Both spectra were saturated at a shorter wavelength, with the saturation wavelength being dependent on the sample, and the order of shift in the onset wavelength of each $\mathrm{TiO}_{2}$ was the same. As a tentative measure of the shift in these spectra, $L_{1 / 2}$ was calculated as the wavelength giving half intensity of saturation and is plotted in Figure 1c. An almost linear relation was observed, indicating that these two kinds of spectra are based on the same phenomenon, i.e., photoabsorption. The reason for the small deviation from a oneto-one straight line might be that PA spectra were affected by thermal properties as well as absorption properties.

In both figures, onset wavelengths shifted from ca. 420 to ca. $380 \mathrm{~nm}$, reflecting their crystal structures: rutile, anatase, and amorphous with band gaps of 3.0 and $3.2 \mathrm{eV}$ and larger, respectively. The spectrum of P25 (Figure 1d), consisting of anatase and rutile crystallites, showed an intermediate character between those of single-phase rutile and anatase samples. An appreciable spectral difference between JRC-TIO-6 and CREL was observed. Both of them are rutile (CR-EL contains a small percentage of anatase), but their primary particle sizes are very different, ca. $15 \mathrm{~nm}$ (JRC-TIO-6) and ca. $200 \mathrm{~nm}$ (CREL). Such a difference may change their light-scattering properties and thereby induce the shift of spectra. Another possible reason for the shift is amorphous phase probably included in JRC-TIO-6 of small crystallites. Samples of rutile and amorphous phase would show an intermediate character between these two phases, similar to that observed for P25. This interesting character of JRC-TIO-6 will be discussed later.

3.2. SB and DB Measurements. A series of sequential SBand DB-PAS measurements was conducted for $\mathrm{TiO}_{2}$ samples. Behavior of PA spectra modified during the series of measurements was categorized into two types, type 1 and type 2 , depending on the nature of $\mathrm{TiO}_{2}$ samples as listed in Table 1.

3.2.1. Type-1 Samples. 3.2.1.1. Representative Type-1 Samples. The first group (type 1) showed an upward shift of the PA spectrum at $>380 \mathrm{~nm}$ under simultaneous continuous UV irradiation (DB measurements) and recovery to the original spectrum in the dark. Figure 2 shows SB- and DB-PA spectra of a representative type-1 sample, JRC-TIO-11. The type-1 samples showed no appreciable differences in the repetition of SB measurements and upward shift of spectra in the DB measurements. Irradiation at greater than ca. $450 \mathrm{~nm}$ instead of continuous UV irradiation induced no such upward shift in the DB measurements, suggesting that band gap excitation induces this upward shift. Purging of amb-air by $\mathrm{N}_{2}$ increased the degree of upward shift and made the rate of recovery in the dark slow. These facts suggest that accumulation of photoexcited electrons, which are possibly consumed by ambient $\mathrm{O}_{2}$ as an electron acceptor, accounts for the PA spectral shift in the visible region. Increase of the PA signal in repeated SB measurements which includes also UV irradiation in part was negligible because of low intensity of monochromatic illumination (ca. $0.2 \mathrm{~mW} \mathrm{~cm}^{-2}$ ) in contrast to the continuous UV irradiation $\left(8.2 \mathrm{~mW} \mathrm{~cm}^{-2}\right)$. A possible difference between amb-air and dry nitrogen is humidity as well as oxygen concentration. Therefore, we have also performed PA measurements under art-air, which contains less humidity. However, no appreciable differences in SB- and DBPA spectra were observed. Thus, the effect of humidity in ambair on PA spectra seemed less significant.

The above-mentioned increase in PA spectra of type-1 samples in DB measurement is attributable to the formation of $\mathrm{Ti}^{3+}$ species under UV irradiation as a counterpart of hole consumption, presumably by residual organic compounds. The presence of such impurities acting as electron donors in $\mathrm{TiO}_{2}$ samples stored under ambient atmosphere has been proved. For example, photoirradiation of in situ platinized and bare $\mathrm{TiO}_{2}$ suspended in pure water liberates hydrogen and carbon dioxide under deaerated and aerated conditions, respectively, suggesting the presence of electron-donating carbon-containing compounds. $\mathrm{O}_{2}$ possibly interferes with this $\mathrm{Ti}^{3+}$ accumulation by both accepting photoexcited electrons and oxidizing once-produced $\mathrm{Ti}^{3+}$. This implies that the upward shift is enhanced under $\mathrm{N}_{2}$ rather than air and that recovery to the original spectrum becomes slower in $\mathrm{N}_{2}$ than that in air. A similar accumulation of $\mathrm{Ti}^{3+}$ has been reported for $\mathrm{TiO}_{2}$ samples under UV irradiation $^{20,28,30}$ or anodic polarization. ${ }^{31}$

The upward shift was enhanced by the presence of hole scavengers because electron accumulation is promoted by effective hole consumption. Therefore, the steady-state intensity of the $\mathrm{Ti}^{3+}$ band depends on the continuous-light intensity and 
TABLE 1: Physical and Chemical Properties of Samples

\begin{tabular}{|c|c|c|c|c|c|c|}
\hline name & $\begin{array}{c}\text { crystal } \\
\text { structure }^{a}\end{array}$ & $\begin{array}{c}\text { types of } \\
\text { PA spectrum }{ }^{b}\end{array}$ & $\begin{array}{c}\text { density of } \mathrm{Ti}^{3+} \\
\quad / \mu \mathrm{mol} \mathrm{g} \mathrm{g}^{-1 c}\end{array}$ & $\begin{array}{c}S_{\mathrm{BET}} \\
/ \mathrm{m}^{2} \mathrm{~g}^{-1}\end{array}$ & $\begin{array}{l}\mathrm{PPS} \\
/ \mathrm{nm}^{d}\end{array}$ & $\begin{array}{l}\text { SPS } \\
/ \mu \mathrm{m}^{e}\end{array}$ \\
\hline JRC-TIO-1 & $\mathrm{A} / \mathrm{R}$ & 1 & $109^{f}$ & $73^{f}$ & 21 & 5.6 \\
\hline JRC-TIO-2 & $\mathrm{A} / \mathrm{R}$ & 1 & $28^{f}$ & $16^{f}$ & 400 & 0.51 \\
\hline JRC-TIO-3 & $\mathrm{R}$ & 1 & $48^{f}$ & $40^{f}$ & 40 & 2.4 \\
\hline JRC-TIO-4 & $\mathrm{A} / \mathrm{R}$ & 1 & $50^{f}$ & $50^{f}$ & 21 & 0.51 \\
\hline JRC-TIO-5 & $\mathrm{R} / \mathrm{A}$ & 1 & $14^{f}$ & $3^{f}$ & 570 & 18 \\
\hline JRC-TIO-6 & $\mathrm{R}$ & 1 & $242^{g}$ & $100^{h}$ & 15 & 2.5 \\
\hline JRC-TIO-7 & A & 2 & $119^{g}$ & $270^{h}$ & 8 & 1.6 \\
\hline JRC-TIO-8 & A & 2 & $118^{g}$ & $338^{h}$ & 6 & 0.24 \\
\hline JRC-TIO-9 & A & 2 & $105^{g}$ & $300^{h}$ & 10 & 0.92 \\
\hline JRC-TIO-10 & A & 2 & $106^{g}$ & $100^{h}$ & 15 & 1.4 \\
\hline JRC-TIO-11 & $\mathrm{A} / \mathrm{R}$ & 1 & $156^{g}$ & $97^{h}$ & 15 & 0.29 \\
\hline JRC-TIO-12 & A & 2 & $111^{g}$ & $290^{h}$ & 6 & 0.79 \\
\hline JRC-TIO-13 & A & 1 & $72^{g}$ & $59^{h}$ & 30 & 1.0 \\
\hline ST-G1 & $\mathrm{R} / \mathrm{A}$ & 1 & $43^{g}$ & $6^{h}$ & 250 & 0.70 \\
\hline ST-G2 & $\mathrm{R} / \mathrm{A}$ & 1 & $47^{g}$ & $3^{h}$ & 500 & 0.86 \\
\hline ST-F1 & $\mathrm{R} / \mathrm{A}$ & 1 & $84^{g}$ & $19^{h}$ & 90 & 0.41 \\
\hline ST-F2 & $\mathrm{R} / \mathrm{A}$ & 1 & $112^{g}$ & $29^{h}$ & 80 & 0.30 \\
\hline ST-F3 & $\mathrm{A} / \mathrm{R}$ & 1 & $108^{g}$ & $37^{h}$ & 50 & 0.34 \\
\hline ST-F5 & $\mathrm{A} / \mathrm{R}$ & 1 & $186^{g}$ & $73^{h}$ & 20 & 0.39 \\
\hline ST-F10 & $R / A$ & 1 & $71^{g}$ & $12^{h}$ & 150 & 0.90 \\
\hline Merck & A & 1 & $25^{f}$ & $13^{f}$ & 169 & 0.44 \\
\hline UV-100 & A & 2 & $98^{f}$ & $250^{f}$ & 9 & 1.4 \\
\hline CR-EL & $\mathrm{R}$ & 1 & $21^{f}$ & $5^{f}$ & 200 & 15 \\
\hline
\end{tabular}

${ }^{a} \mathrm{~A}, \mathrm{R}, \mathrm{A} / \mathrm{R}$, and $\mathrm{R} / \mathrm{A}$ in the column of crystal structure denote the predominant crystal phase, pure anatase, pure rutile, predominantly anatase, and predominantly rutile, respectively. ${ }^{b} 1$ : showing an upward shift of the PA spectrum at $>380 \mathrm{~nm}$ by UV irradiation, 2 : showing a PA band at 380-500 nm by UV irradiation. ${ }^{c}$ Measured by the photochemical method (see text). ${ }^{d}$ Primary particle size. ${ }^{e}$ Secondary particle size. ${ }^{f}$ Reported in ref 5. ${ }^{g}$ Reported in ref $27 .{ }^{h}$ Reported in ref 45 .

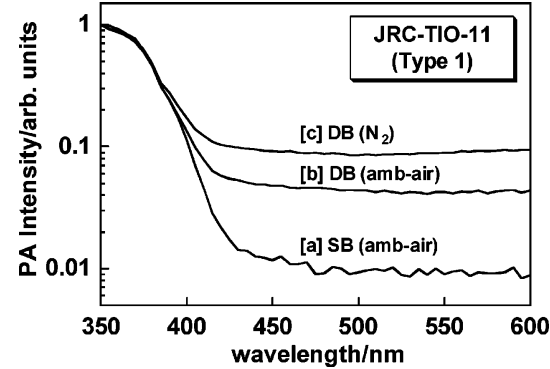

Figure 2. PA spectra of JRC-TIO-11. (Curve a) SB spectrum measured in amb-air. Final-state spectrum by repetition of DB measurements (curve b) in amb-air and (curve c) under $\mathrm{N}_{2}$.

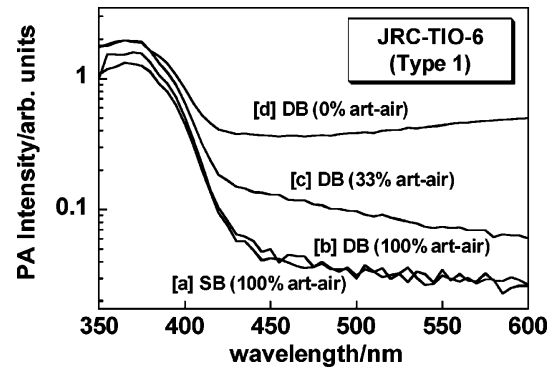

Figure 3. PA spectra of JRC-TIO-6. (Curve a) SB spectrum measured in art-air. Final-state spectrum by repetition of DB measurements (curve b) in art-air, (curve c) in $30 \%$ art-air diluted with Ar, and (curve d) under Ar.

amount of adsorbed $\mathrm{O}_{2}$ and hole scavengers. This will be discussed later in relation to the time course of the DB-PA signal.

3.2.1.2. Characteristics of JRC-TIO-6. Most of the type-1 samples showed similar upward shifts regardless of chemical and physical properties, but JRC-TIO-6 showed slightly different spectral behavior (Figure 3). For this sample, SB measurements did not cause any appreciable change in PA spectra and a negligible upward shift could also be obtained in art-air even under DB conditions (Figure 3b). When air was diluted 3 times by Ar, DB measurement induced an upward shift, the extent of which was slightly larger in a shorter wavelength (450-500 $\mathrm{nm}$, Figure 3c), and an almost flat shift, as a characteristic of type-1 samples, was observed in the DB measurement under deaerated conditions. As has been reported briefly in the previous paper, ${ }^{27} \mathrm{DB}$ measurement using the standard cell (smaller head space) gave an appreciable PA signal increase, which was similar to that of Figure $3 \mathrm{c}$, even under air, while, in the present study using the gas-exchangeable cell (larger head space), no appreciable PA signal increase was obtained. The difference might be caused by the difference in the amount of $\mathrm{O}_{2}$ in a head space in the cells, and this suggests that JRCTIO-6 has higher sensitivity to $\mathrm{O}_{2}$ and strongly depends on amount of ambient $\mathrm{O}_{2}$ in the PA cell. For type- 1 samples, the shift due to the accumulation of $\mathrm{Ti}^{3+}$ might be retarded by $\mathrm{O}_{2}$. The fact that the standard cell contains a smaller amount of $\mathrm{O}_{2}$ and the fact that dilution of air induced the shift suggest that JRC-TIO-6, showing higher sensitivity toward $\mathrm{O}_{2}$, adsorbs a relatively large amount of $\mathrm{O}_{2}$ presumably because of its relatively large specific surface area.

3.2.2. Type-2 Samples. 3.2.2.1. Spectral Behavior. The second group (type 2) includes anatase samples of relatively large specific surface area $\left(>250 \mathrm{~m}^{2} \mathrm{~g}^{-1}\right)$, e.g., Hombikat UV-100, JRC-TIO-7-10 or 12. Figure 4 shows SB- and DB-PA spectra of JRC-TIO-12 as a representative type- 2 sample. As a general trend, type-2 samples showed a PA signal increase at 380$500 \mathrm{~nm}$ in repeated SB measurements in the presence of $\mathrm{O}_{2}$ (amb-air), but not in the presence of $\mathrm{N}_{2}$, and this band was also observed in subsequent $\mathrm{DB}$ measurements but decreased in repeated DB measurements to finally give a type-1-like flat shift in $\mathrm{N}_{2}$. Growth of the 380-500 $\mathrm{nm}$ band was observed in the SB scan of wavelength of $<400 \mathrm{~nm}$. These results indicate that this PA signal was induced by band gap excitation with the aid of $\mathrm{O}_{2}$ and was decreased by intensive irradiation. On the other hand, the upward shift at $>400 \mathrm{~nm}$ under deaerated DB conditions was similar to that observed for type-1 samples, and this shift is attributed to $\mathrm{Ti}^{3+}$ production under less aerated 


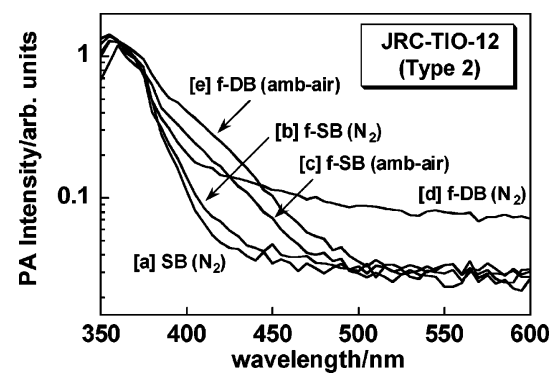

Figure 4. PA spectra of JRC-TIO-12. (Curve a) Initial-state spectrum by $\mathrm{SB}$ measurement under $\mathrm{N}_{2}$, final-state spectrum by repetition of $\mathrm{SB}$ measurements (curve b) under $\mathrm{N}_{2}$ and (curve c) in amb-air, final-state spectrum by repetition of DB measurements (curve d) under $\mathrm{N}_{2}$ and (curve e) in amb-air.

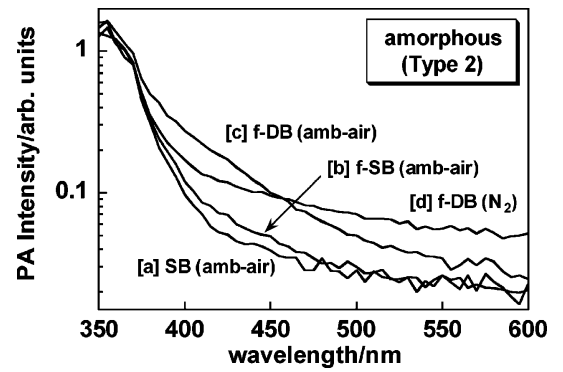

Figure 5. PA spectra of Wako amorphous. (Curve a) Initial-state spectrum by SB measurement in amb-air, (curve b) final-state spectrum by repetition of SB measurements in amb-air, final-state spectrum by repetition of DB measurements (curve c) under $\mathrm{N}_{2}$ and (curve d) in amb-air.

conditions. Thus, type-2 samples were shown to be sensitive to ambient $\mathrm{O}_{2}$ rather than type- 1 samples and to give a PA band at $380-500 \mathrm{~nm}$.

Similar behavior was also detected for a Wako amorphous sample (Figure 5), exhibiting a 380-500 nm band mainly in subsequent DB measurements. Taking the larger band gap of amorphous $\mathrm{TiO}_{2}$ into account, the observed slow rate of the 380-500 $\mathrm{nm}$ band appearance in repeated SB measurements is accounted for by a smaller number of photons absorbed during SB measurements.

3.2.2.2. Assignment of the PA Band at $380-500 \mathrm{~nm}$. There are two possible assignments of the PA band at $380-500 \mathrm{~nm}$. The first one is photoabsorption of trapped holes, which were produced by stabilization of positive holes in certain states after rapid electron transfer to an acceptor on the $\mathrm{TiO}_{2}$ surface, such as $\mathrm{O}_{2}$. The effect of $\mathrm{O}_{2}$ and hole scavengers on the PA band opposite to that of $\mathrm{Ti}^{3+}$ species also supports the assignment of this band to trapped holes or their derivatives. A similar assignment of a transient absorption peak at ca. $430 \mathrm{~nm}$ has been reported on time-resolved spectroscopic studies on $\mathrm{TiO}_{2}$ samples in the presence of electron scavengers. ${ }^{15}$ However, some studies reported different results, ${ }^{16,20}$ since these peaks and shapes of spectra are sensitive to surface conditions and kinds of scavengers. ${ }^{20}$ The lifetime of these species was much shorter than that of the present study presumably due to differences of experimental conditions. A possible structure of the trapped hole is surface-bound hydroxyl radicals, though we do not yet have evidence supporting this.

Another possible assignment of the $380-500 \mathrm{~nm}$ band is surface peroxy species, since it was reported that treatment of $\mathrm{TiO}_{2}$ with aqueous $\mathrm{H}_{2} \mathrm{O}_{2}$ led to the appearance of absorption at 350-500 nm. ${ }^{32-35}$ As has been reported previously, ${ }^{34}$ type-1 samples (JRC-TIO-3 and JRC-TIO-5) also showed development of absorption at $380-500 \mathrm{~nm}$ by the $\mathrm{H}_{2} \mathrm{O}_{2}$ treatment, while these

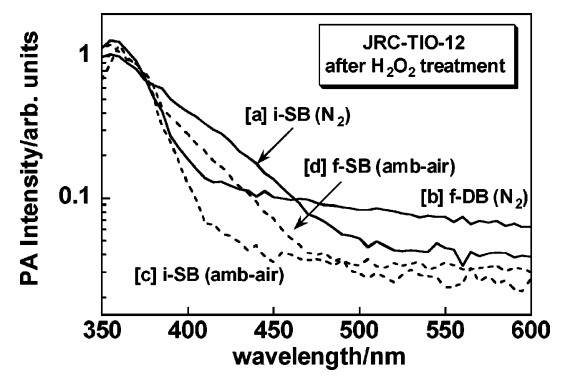

Figure 6. PA spectra of JRC-TIO-12 after $\mathrm{H}_{2} \mathrm{O}_{2}$ treatment. (Curve a) Initial-state $\mathrm{SB}$ and (curve b) final-state $\mathrm{DB}$ spectrum under $\mathrm{N}_{2}$. (Curve c) Initial-state SB and (curve d) final-state SB spectrum of untreated sample under amb-air.

type-1 samples did not give such absorption in the DB-PAS measurements. This suggests that type- 1 samples produce less amount of $\mathrm{H}_{2} \mathrm{O}_{2}$ under UV irradiation. Figure 6 shows the SBand DB-PA spectra of JRC-TIO-12 after $\mathrm{H}_{2} \mathrm{O}_{2}$ treatment. In SB-PAS measurements a similar PA band was detected as observed by repetition of SB measurement for the untreated sample. $\mathrm{H}_{2} \mathrm{O}_{2}$ can be produced by reaction of photoexcited electrons with $\mathrm{O}_{2}$ and proton on the $\mathrm{TiO}_{2}$ surface, ${ }^{36}$ and ESR studies also have suggested the photoinduced liberation of peroxide species on $\mathrm{TiO}_{2}$ in the presence of $\mathrm{O}_{2},{ }^{10}$ though we have no information on the origin from the present study. An alternative mechanism of $\mathrm{H}_{2} \mathrm{O}_{2}$ formation is coupling of hydroxyl radicals. However, judging from the fact that the PA increase was hardly observed by repetition of the SB measurements under $\mathrm{N}_{2}$ (Figure $4 \mathrm{~d}$ ) where hydroxyl radical coupling reaction to $\mathrm{H}_{2} \mathrm{O}_{2}$ may proceed, generation of $\mathrm{H}_{2} \mathrm{O}_{2}$ through this mechanism can be ruled out. Though another mechanism of formation of titanium peroxy species through the mechanism not including $\mathrm{H}_{2} \mathrm{O}_{2}$ or hydroxyl radicals has been proposed by Nakamura et al., ${ }^{37}$ we have at present no information to distinguish this reaction path from the above-mentioned $\mathrm{H}_{2} \mathrm{O}_{2}$ mechanism since both give the same products, surface peroxy species. On the other hand, in the DB measurement the PA band at 380-500 $\mathrm{nm}$ decreased under intensive UV irradiation, and another PA band above $380 \mathrm{~nm}$ appeared as observed for the untreated one. These results suggest that excess accumulation of photogenerated electrons reduced surface peroxy species, and then they produced $\mathrm{Ti}^{3+}$ species.

As described in the initial part of this section, all of the type-2 samples consist of anatase crystallites of relatively large specific surface area $\left(>250 \mathrm{~m}^{2} \mathrm{~g}^{-1}\right)$, and thereby, they possess large amounts of surface hydroxyls as reported in studies on infrared spectroscopy, ${ }^{10,38}$ thermogravimetry, ${ }^{39-41}$ and ${ }^{1} \mathrm{H}$ NMR, ${ }^{42,43}$ since the surface density of hydroxyls on $\mathrm{TiO}_{2}$ has been reported to be almost constant regardless of their particle size. ${ }^{44}$ In these samples, photoinduced formation of two possible origins for the 380-500 $\mathrm{nm}$ band can be enhanced, i.e., a large amount of adsorbed $\mathrm{O}_{2}$ accelerates accumulation of positive holes by reacting with photoexcited electrons and resulting superoxide anion $\left(\mathrm{O}_{2}^{-} \cdot\right)$ or $\mathrm{H}_{2} \mathrm{O}_{2}$ produces surface peroxy species. A large amount of surface hydroxyls may also enhance the hole trapping as well as the reaction of $\mathrm{H}_{2} \mathrm{O}_{2}$. Under these conditions, contaminated surface organic compounds might be consumed off.

We recently reported the activity of electrons once accumulated in $\mathrm{TiO}_{2}$ as a form of $\mathrm{Ti}^{3+}$ and suggested that electrons in type-2 samples have higher mobility than do those in type-1 samples. ${ }^{45}$ Considering physical properties of type- 2 samples, the higher mobility is attributable to a large number of adsorption sites (large surface area) and short distance to the 


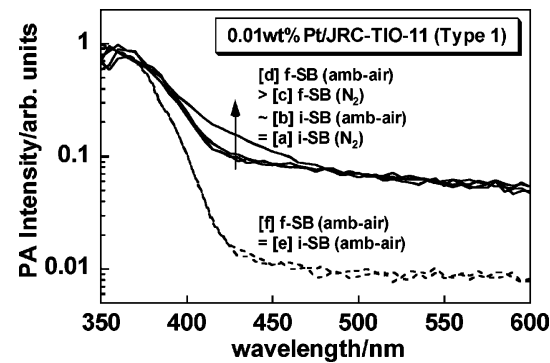

Figure 7. PA spectra of JRC-TIO-11 (representative type-1 sample) with 0.01 wt $\%$ deposited Pt. Initial-state SB spectrum under (curve a) $\mathrm{N}_{2}$ and (curve b) amb-air. Final-state SB spectrum under (curve c) $\mathrm{N}_{2}$ and (curve d) amb-air. (Curve e) Initial- and (curve f) final-state SB spectrum under amb-air for JRC-TIO-11 without deposited Pt.

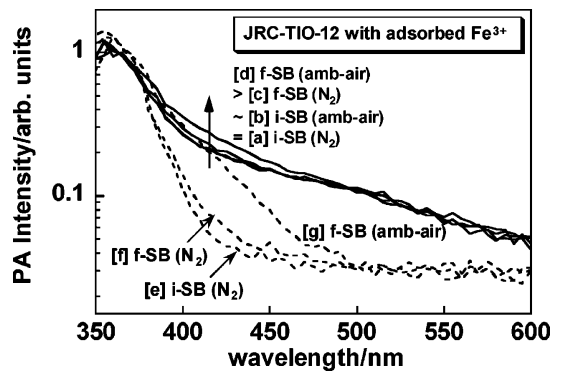

Figure 8. PA spectra of JRC-TIO-12 with adsorbed $\mathrm{Fe}^{3+}$. Initial-state $\mathrm{SB}$ spectrum under (curve a) $\mathrm{N}_{2}$ and (curve b) amb-air. Final-state $\mathrm{SB}$ spectrum under (curve c) $\mathrm{N}_{2}$ and (curve d) amb-air. (Curve e) Initialand (curve f) final-state SB spectrum under $\mathrm{N}_{2}$ and (curve g) finalstate SB spectrum under amb-air for JRC-TIO-12 without adsorbed $\mathrm{Fe}^{3+}$.

surface (small primary particle size). These results also support the above-mentioned behavior of type-2 samples.

Figure 7 shows the SB- and DB-PA spectra of JRC-TIO-11 (representative type-1 sample) with $0.01 \mathrm{wt} \%$ of deposited Pt. In initial SB measurement the PA intensity at $>380 \mathrm{~nm}$ for this platinized sample is larger than that for the bare one due to the influence of deposited $\mathrm{Pt}$ on the $\mathrm{TiO}_{2}$ surface, and repetition of the SB measurements induced a similar increase of the PA intensity at $380-500 \mathrm{~nm}$ as seen for type- 2 samples. This indicates that deposited $\mathrm{Pt}$ on $\mathrm{TiO}_{2}$ surface worked as an electron pool and accelerated the electron transfer to adsorbed $\mathrm{O}_{2}$ on the $\mathrm{TiO}_{2}$ surface, resulting in the formation of trapped hole or surface peroxy species.

In order to identify the assignment of the PA band at 380$500 \mathrm{~nm}$, behaviors of PA spectra for type-2 samples with adsorbed $\mathrm{Fe}^{3+}$ were studied. Since $\mathrm{Fe}^{3+}$ is expected to work as electron acceptor, photoexcited-electron transfer to $\mathrm{Fe}^{3+}$ may produce trapped holes even in the absence of $\mathrm{O}_{2}$. Thus, if the PA band at $380-500 \mathrm{~nm}$ is attributed to absorption of a trapped hole, it should appear under the deaerated condition by repetition of the SB measurement (under weaker photoexcitation). Figure 8 shows PA spectra of JRC-TIO-12 with adsorbed $\mathrm{Fe}^{3+}$. Only the final-state PA spectrum under amb-air showed the PA band at $380-500 \mathrm{~nm}$ in the presence of a strong electron acceptor, $\mathrm{Fe}^{3+}$. This indicates that $\mathrm{O}_{2}$ is indispensable for generation of the PA band, and the PA band is attributable to production of surface peroxy species but not trapped holes.

3.2.2.3. Type-2 Samples with Methanol. For type-2 samples, it is thought that a negligible amount of contaminated organic compounds, electron donors, remain on the surface during the PAS measurements. In the preceding paper, we reported that addition of methanol vapor to the atmosphere modified the PA spectra of type- 2 samples, especially under DB conditions. For
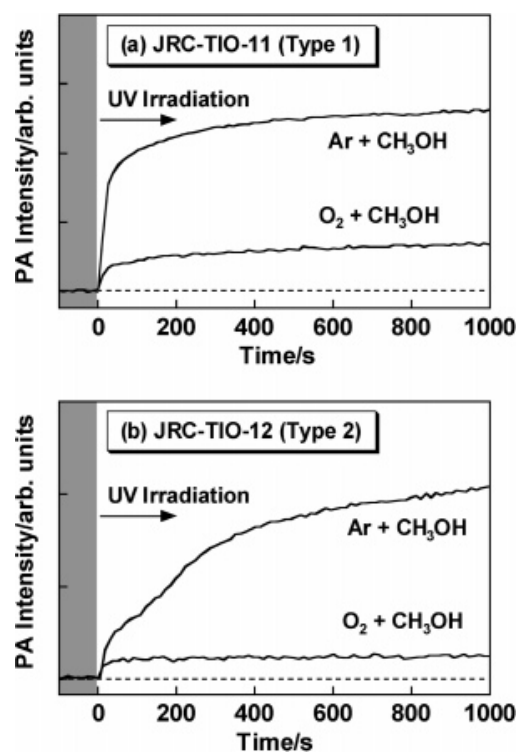

Figure 9. Time-course curves of PA signal of (a) JRC-TIO-11 and (b) JRC-TIO-12 under $\mathrm{Ar}+\mathrm{CH}_{3} \mathrm{OH}$ and $\mathrm{O}_{2}+\mathrm{CH}_{3} \mathrm{OH}$ at $530 \mathrm{~nm}$.

example, the DB-PA spectrum of a representative type-2 sample, JRC-TIO-12, became similar to that of type-1 samples; rather flat spectra were obtained in the presence of methanol vapor. A plausible mechanism is that methanol, a strong electron donor, captures as-formed or trapped positive holes to leave a large number of electrons, at least some of which are accumulated as a form of $\mathrm{Ti}^{3+}$ as observed for type-1 samples. Thus, we have shown that the present DB-PAS enables detection of the intermediate species in their steady state under continuous photoirradiation. In the following section, changes in DB-PA spectra during photoirradiation, i.e., results of time-resolved studies, will be reported.

3.3. Time-Resolved Measurements. 3.3.1. Time-Course Curve with UV Irradiation. 3.3.1.1. Time-Course Profile. Timeresolved measurements were conducted under an $\mathrm{O}_{2}+\mathrm{CH}_{3}$ $\mathrm{OH}$ or $\mathrm{Ar}+\mathrm{CH}_{3} \mathrm{OH}$ atmosphere. To exclude the influence of photoabsorption by trapped holes or peroxy species at 380$500 \mathrm{~nm}$, the PA signal was recorded at a fixed wavelength of $530 \mathrm{~nm}$, at which the signal is almost solely assignable to $\mathrm{Ti}^{3+}$. Figure 9 shows time-course curves of the PA signal for representative type- 1 and type-2 samples. Under simultaneous UV irradiation, the PA intensity increased owing to generation and accumulation of $\mathrm{Ti}^{3+}$ and approached saturation over a period of $1000 \mathrm{~s}$, suggesting that the number of sites giving $\mathrm{Ti}^{3+}$ is limited to a given value depending on the kind of $\mathrm{TiO}_{2}$ sample. Type-1 samples showed similar curves under both $\mathrm{O}_{2}$ $+\mathrm{CH}_{3} \mathrm{OH}$ and $\mathrm{Ar}+\mathrm{CH}_{3} \mathrm{OH}$ conditions, though their saturation limits were appreciably different. The lower intensity under the former condition, presumably due to retardation of $\mathrm{Ti}^{3+}$ accumulation by $\mathrm{O}_{2}$, is consistent with the results shown in Figure 2 , where the PA spectrum was upward shifted by purging of air by $\mathrm{N}_{2}$. Such saturation is possibly interpreted by the balance of forward and backward reactions of $\mathrm{Ti}^{3+}$ production, i.e., capture of electrons by $\mathrm{Ti}^{4+}$ sites and reoxidation by $\mathrm{O}_{2}$. On the other hand, type-2 samples showed slightly but appreciably different behavior of the time course of the PA signal; the rise was relatively slow, and a two-step increase was observed under $\mathrm{Ar}+\mathrm{CH}_{3} \mathrm{OH}$ conditions. In order to interpret this behavior, we assumed that an appreciable amount of surface-adsorbed $\mathrm{O}_{2}$ remains even after purging of air by $\mathrm{Ar}$ and that the remaining $\mathrm{O}_{2}$ retarded the $\mathrm{Ti}^{3+}$ production until this is consumed thoroughly. 

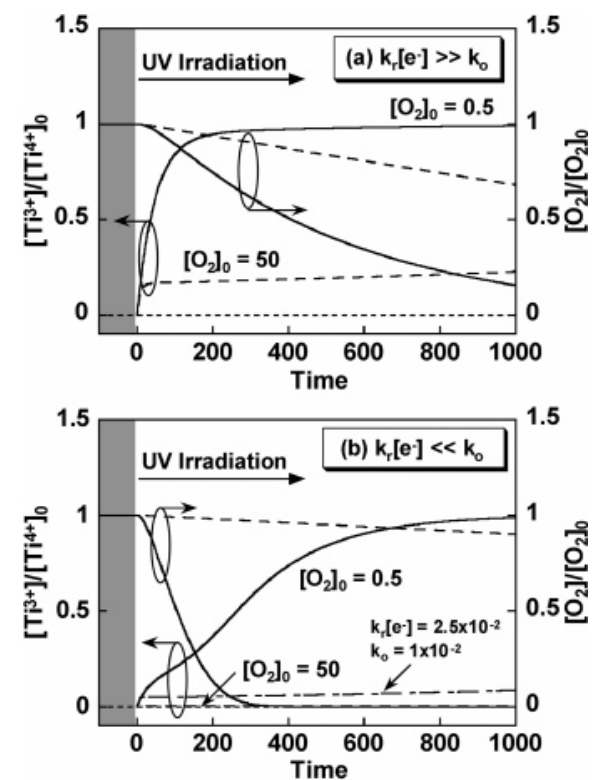

Figure 10. Time-course curves of $\mathrm{Ti}^{3+}$ formation and $\mathrm{O}_{2}$ consumption reproduced by numerical simulations. Simulation parameters were (a) $k_{\mathrm{r}}\left[\mathrm{e}^{-}\right]=2 \times 10^{-2}, k_{\mathrm{o}}=2 \times 10^{-3}$ and (b) $k_{\mathrm{r}}\left[\mathrm{e}^{-}\right]=5 \times 10^{-3}, k_{\mathrm{o}}=5$ $\times 10^{-2}$.

3.3.1.2. Simulation of Time-Course Profile. For the simulation, we simplified the reaction kinetics of $\mathrm{Ti}^{3+}$ accumulation by assuming the following two elementary steps.

$$
\begin{gathered}
\mathrm{Ti}^{4+}+\mathrm{e}^{-} \stackrel{k_{\mathrm{r}}}{\longrightarrow} \mathrm{Ti}^{3+} \\
\mathrm{Ti}^{3+}+\mathrm{O}_{2} \stackrel{k_{\mathrm{o}}}{\longrightarrow} \mathrm{Ti}^{4+}+\mathrm{O}_{2}{ }^{-} \bullet
\end{gathered}
$$

where $\mathrm{Ti}^{4+}$ shows the site to be reduced to $\mathrm{Ti}^{3+}$, and its density $\left(\left[\mathrm{Ti}^{4+}\right]\right)$ can be expressed using the initial density $\left[\mathrm{Ti}^{4+}\right]_{0}$ as follows:

$$
\left[\mathrm{Ti}^{4+}\right]=\left[\mathrm{Ti}^{4+}\right]_{0}-\left[\mathrm{Ti}^{3+}\right]
$$

Then, a steady-state concentration of electrons $\left(\left[\mathrm{e}^{-}\right]\right)$is assumed since positive holes, liberated simultaneously with photoexcited electrons, are consumed rapidly ${ }^{17,18}$ by methanol and their recombination has been reported to be rather fast. ${ }^{3}$ On the basis of these simplified assumptions, the rates of $\mathrm{Ti}^{3+}$ accumulation and $\mathrm{O}_{2}$ consumption are given by

$$
\begin{gathered}
\frac{\mathrm{d}\left[\mathrm{Ti}^{3+}\right]}{\mathrm{d} t}=k_{\mathrm{r}}\left[\mathrm{Ti}^{4+}\right]\left[\mathrm{e}^{-}\right]-k_{\mathrm{o}}\left[\mathrm{Ti}^{3+}\right]\left[\mathrm{O}_{2}\right] \\
\frac{\mathrm{d}\left[\mathrm{O}_{2}\right]}{\mathrm{d} t}=-k_{\mathrm{o}}\left[\mathrm{Ti}^{3+}\right]\left[\mathrm{O}_{2}\right]
\end{gathered}
$$

where $k_{\mathrm{r}}$ is a rate constant of reduction for $\mathrm{Ti}^{4+}$ and $k_{\mathrm{o}}$ is a rate constant of oxidation for $\mathrm{Ti}^{3+}$.

Figure 10 shows results of numerical simulation of timecourse curves for production of $\mathrm{Ti}^{3+}$ and consumption of $\mathrm{O}_{2}$ using the fourth-order Runge-Kutta method based on eqs 3-5. These numerical calculation results reproduced time-course curves that are similar to the experimental results for both type-1 and type-2 samples (Figure 9), with only a small difference between experimental results and results of calculation due to simplification of the reaction process. An exception was the time course of type 2 under $\mathrm{O}_{2}$, which could be reproduced if relatively large $k_{\mathrm{r}}\left[\mathrm{e}^{-}\right]$and $k_{\mathrm{o}}$ of $2.5 \times 10^{-2}$ and $1 \times 10^{-2}$, respectively ( 5 times larger and smaller than those used for the curve with parameters of $\left.\left[\mathrm{O}_{2}\right]_{0}=0.5\right)$, were used. The timecourse curve simulated with parameters of $k_{\mathrm{r}}\left[\mathrm{e}^{-}\right] \ll k_{\mathrm{o}}$ and relatively large ( $1 \%$ to $\mathrm{O}_{2}$ conditions) initial amount of a trace of $\mathrm{O}_{2}$ showed a two-step increase, when we assumed the parameters in the narrow range of values. This two-step increase can be explained qualitatively as follows. In the first step increase $(0-200 \mathrm{~s})$, electron transferred to a trace of $\mathrm{O}_{2}$ retarded electron accumulation on $\mathrm{TiO}_{2}$ until $\mathrm{O}_{2}$ was consumed completely. In the second step increase (>200 s), $\mathrm{Ti}^{3+}$ species were rapidly produced by electron accumulation, followed by saturation due to limitation of the number of sites.

On the other hand, in the case of $k_{\mathrm{r}}\left[\mathrm{e}^{-}\right] \gg k_{\mathrm{o}}$ (Figure 10a), the one-step increase was reproduced, since a large part of $\mathrm{O}_{2}$ was left unreacted when most of the $\mathrm{Ti}^{4+}$ was reduced to $\mathrm{Ti}^{3+}$ even assuming that only $1 \%$ of $\mathrm{O}_{2}$ was included in Ar. Thus, the similarity between simulation and experimental results suggests that $\mathrm{Ti}^{3+}$ species for type-2 samples have larger reactivity toward $\mathrm{O}_{2}$, or a large amount of $\mathrm{O}_{2}$ is adsorbed on type- 2 samples, compared to that of type- 1 samples.

3.3.1.3. Estimation of $\mathrm{Ti}^{3+}$ Density. In order to estimate the saturation limit $\left(I_{530}\right)$, corresponding to the maximum yield of $\mathrm{Ti}^{3+}$ in each sample, the time-course curve of PA intensity at $530 \mathrm{~nm}$ was fitted, for convenience, to a set of three exponential functions $I$ (eq 6) for one-step increase (type-1 sample) and $I$ (eq 7) for two-step increase (type-2 sample).

$$
\begin{gathered}
I(t)=\sum_{i=1}^{3} a_{i}\left[1-\exp \left(-t / \tau_{i}\right)\right] \\
I(t)=a_{1}\left[1-\exp \left(-t / \tau_{1}\right)\right]+2 a_{2} /\left[1+\exp \left\{-\left(t-t_{2}\right) / \tau_{2}\right\}\right]+ \\
a_{3}\left[1-\exp \left\{-(t-T) / \tau_{3}\right\}\right] \theta(T)
\end{gathered}
$$

where $\theta(\mathrm{t})$ is a step function. $I_{530}$ was obtained from summation of their saturated values, $a_{1}-a_{3}$ (eq 8 ).

$$
I_{530}=I(t=\infty)=\sum_{i=1}^{3} a_{i}
$$

Figure 11 shows the correlation of $I_{530}$ measured under (Figure 11a) $\mathrm{Ar}+\mathrm{CH}_{3} \mathrm{OH}$ and (Figure 11b) $\mathrm{O}_{2}+\mathrm{CH}_{3} \mathrm{OH}$ conditions with the density of $\mathrm{Ti}^{3+}$ measured photochemically. ${ }^{27}$ The $I_{530}$ values of both type- 1 and type- 2 samples were nearly proportional to the $\mathrm{Ti}^{3+}$ density under $\mathrm{Ar}+\mathrm{CH}_{3} \mathrm{OH}$ conditions (Figure 11a), suggesting that assignment of the PA signal to $\mathrm{Ti}^{3+}$ is reasonable. A similar linear relation was obtained in our previous study with irradiation of a light beam from a Xe lamp passing through a UV-D33S optical filter as a continuous UV-light source $\left(300-400 \mathrm{~nm}, 8.2 \mathrm{~mW} \mathrm{~cm}^{-2}\right) .{ }^{27}$ Thus, it is thought that UV-LED $\left(365 \mathrm{~nm}, 2.8 \mathrm{~mW} \mathrm{~cm}^{-2}\right)$ can be an alternative continuous UV-light source, and it is preferable for miniaturization and easy operation of a PAS system. In comparison to the photochemical method, the present PAS technique has several advantages: (1) the time required for estimation is much shorter than that for estimation by the photochemical method, which needs more than 1 day, (2) no redox reagent, such as methylviologen, is needed, (3) the samples can be kept dry and can be recovered, (4) the time course of $\mathrm{Ti}^{3+}$ accumulation can be monitored, and (5) the difference in photoreactivity of $\mathrm{TiO}_{2}$ samples can be detected, as type- 1 and type- 2 samples.

Similar time-course curves of $\mathrm{Ti}^{3+}$ production and a linear relationship between saturated $\mathrm{Ti}^{3+}$ amounts obtained by using the present DB-PA technique and the photochemical one were 

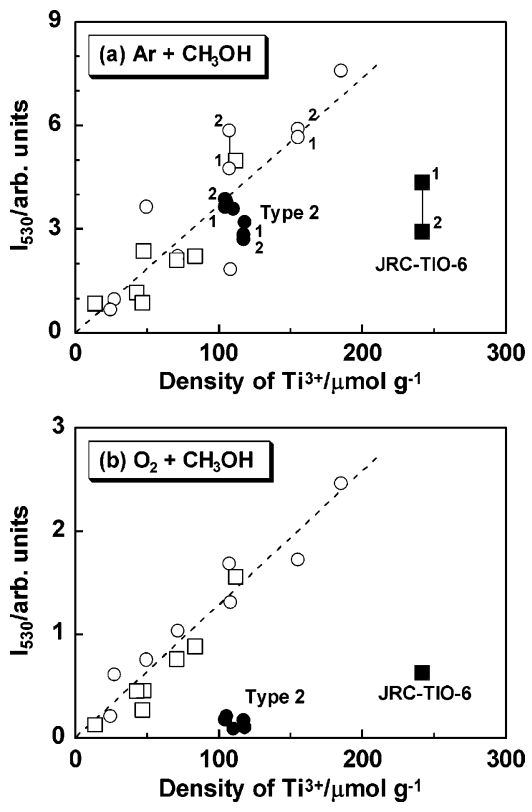

Figure 11. Relation between the saturation limit of PA intensity $\left(I_{530}\right)$ under (a) $\mathrm{Ar}+\mathrm{CH}_{3} \mathrm{OH}$ and (b) $\mathrm{O}_{2}+\mathrm{CH}_{3} \mathrm{OH}$ and density of $\mathrm{Ti}^{3+}$. Predominantly anatase $(\bigcirc)$, predominantly rutile $(\square)$, type-2 sample $(\bullet)$ JRC-TIO-6 (ם). Numbers "1" and " 2 " in panel a show $I_{530}$ in repeated experiments which were operated to check the reproducibility.

also observed with modulated light of wavelength at 455 and $625 \mathrm{~nm}$ under $\mathrm{Ar}+\mathrm{CH}_{3} \mathrm{OH}$. This suggests that assignment of the PA signal above $400 \mathrm{~nm}$ to $\mathrm{Ti}^{3+}$ is reasonable, and the trapped holes or surface peroxide species disappear under $\mathrm{Ar}$ $+\mathrm{CH}_{3} \mathrm{OH}$. Under $\mathrm{O}_{2}+\mathrm{CH}_{3} \mathrm{OH}$ conditions, on the other hand, $I_{530}$ for type-2 samples was much smaller than that under $\mathrm{Ar}+$ $\mathrm{CH}_{3} \mathrm{OH}$, resulting in deviation of the plots from the linear master line (Figure $11 \mathrm{~b}$ ), and $I_{455}$ was larger than $I_{530}$ under $\mathrm{O}_{2}+\mathrm{CH}_{3}$ $\mathrm{OH}$, the latter of which might correspond to the detection of trapped holes or surface peroxy species as shown in Figure 4. These results are attributable to the relatively high sensitivity of type- 2 samples toward $\mathrm{O}_{2}$ and low stability of photogenerated $\mathrm{Ti}^{3+}$ species on those samples in the presence of $\mathrm{O}_{2}$. Therefore, estimation of the $\mathrm{Ti}^{3+}$ saturation limit by numerical calculation cannot be applied to data of type- 2 samples in the presence of $\mathrm{O}_{2}$.

The only exception from the linear relation in Figure 11 was JRC-TIO-6, which showed a different spectral response as described in the previous section. Considering that a different light source was used for electron accumulation on $\mathrm{TiO}_{2}(\mathrm{a}$ mercury lamp for the photochemical method and a Xe lamp or an LED for the present PA method), steady-state generation of electrons might not be sufficient for electron accumulation on JRC-TIO-6 due to a high recombination rate or a large amount of amorphous phase that has a larger band gap energy.

Reproducibility of data was examined for some selected samples as shown in Figure 11a. Except of the sample JRCTIO-6, the reproducibility seemed high enough to be used for quantitative analyses.

\section{Conclusions}

We have recently proposed that the PA technique is an alternative feasible method for estimation of $\mathrm{Ti}^{3+}$ density on $\mathrm{TiO}_{2}$ powders. ${ }^{27}$ Several evaluation methods on $\mathrm{Ti}^{3+}$ species in $\mathrm{TiO}_{2}$ powders, films, and crystal surfaces have been reported on ESR, ${ }^{6-12}$ DRIFTS, ${ }^{13,14}$ X-ray photoelectron spectroscopy (XPS), ${ }^{30,46-48}$ and ultraviolet photoelectron spectroscopy (UPS). ${ }^{47,48}$ Although these measurements provide information on chemical structures or energy states, most of the experiments require pretreatment or special conditions. Ultrafast spectroscopy has been employed to survey the dynamics of $\mathrm{Ti}^{3+}$ species without special conditions, but it requires excitation with a highpower light pulse, which may induce unusual photocatalytic reactions. In the present study, we carried out PA spectroscopic analysis of the behavior of $\mathrm{Ti}^{3+}$ species under ordinary photocatalytic conditions by controlling the atmosphere, and we analyzed the kinetics of photoinduced $\mathrm{Ti}^{3+}$. Furthermore, DBPA technique is possibly suitable for accurate estimation of detection of $\mathrm{Ti}^{3+}$ species in $\mathrm{TiO}_{2}$ powders since PA detection is more sensitive and less influenced by light scattering. The results shown in this paper encourage the usage of DB-PAS as a powerful tool for analysis of photocatalyst characteristics, e.g., crystal defect measurement.

Acknowledgment. The authors gratefully acknowledge Professor Taro Toyoda (The University of Electro-Communications) for his help in the design of PAS setups. This work was partly supported by a Grant-in-Aid for Scientific Research on Priority Areas (417) from the Ministry of Education, Culture, Sports, Science and Technology (MEXT) of the Japanese Government. We thank Professor Wataru Ueda (Catalysis Research Center, Hokkaido University) for permission of use of an X-ray diffractometer.

\section{References and Notes}

(1) Hoffmann, M. R.; Martin, S. T.; Choi, W.; Bahnemann, D. W. Chem. Rev. 1995, 95, 69 .

(2) Fujishima, A.; Rao, T. N.; Tryk, D. A. J. Photochem. Photobiol., $C$ 2000, 1,79 .

(3) Ohtani, B.; Bowman, R. M.; Colombo, D. P., Jr.; Kominami, H.; Noguchi, H.; Uosaki, K. Chem. Lett. 1998, 27, 579.

(4) Diebold, U. Surf. Sci. Rep. 2003, 48, 53.

(5) Ikeda, S.; Sugiyama, N.; Murakami, S.; Kominami, H.; Kera, Y.; Noguchi, H.; Uosaki, K.; Torimoto, T.; Ohtani, B. Phys. Chem. Chem. Phys. 2003, 5,778 .

(6) Howe, R. F.; Grätzel, M. J. Phys. Chem. 1985, 89, 4495.

(7) Howe, R. F.; Grätzel, M. J. Phys. Chem. 1987, 91, 3906.

(8) Mimic, O. I.; Zhang, Y.; Cromack, K. R.; Trifunac, A. D.; Thurnauer, M. C. J. Phys. Chem. 1993, 97, 7277.

(9) Mimic, O. I.; Zhang, Y.; Cromack, K. R.; Trifunac, A. D. Thurnauer, M. C. J. Phys. Chem. 1993, 97, 13284.

(10) Coronado, J. M.; Maria, A. J.; Conesa, J. C.; Yeung, K. L.; Augugliaro, V.; Soria, J. Langmuir 2001, 17, 5368.

(11) Berger, T.; Sterrer, M.; Diwald, O.; Knözinger, E.; Panayotov, D.; Thompson, T. L.; Yates, J. T., Jr. J. Phys. Chem. B 2005, 109, 6061.

(12) Berger, T.; Sterrer, M.; Diwald, O.; Knözinger, E. ChemPhysChem 2005, 6, 2104.

(13) Szczepankiewicz, S. H.; Colussi, A. J.; Hoffmann, M. R. J. Phys Chem. B 2000, 104, 9842.

(14) Szczepankiewicz, S. H.; Moss, J. A.; Hoffmann, M. R. J. Phys. Chem. B 2002, 106, 7654.

(15) Bahnemann, D.; Henglein, A.; Spanhel, L. Faraday Discuss. Chem. Soc. 1984, 78, 151.

(16) Bahnemann, D.; Henglein, A.; Lili, J.; Spanhel, L. J. Phys. Chem. 1984, 88, 709.

(17) Yamakata, A.; Ishibashi, T.; Ohnishi, H. J. Phys. Chem. B 2001, 105,7258 .

(18) Yamakata, A.; Ishibashi, T.; Ohnishi, H. J. Phys. Chem. B 2002, $106,9122$.

(19) Furube, A.; Asahi, T.; Masuhara, H.; Yamashita, H.; Anpo, M. $J$ Phys. Chem. B 1999, 103, 3120.

(20) Yoshihara, T.; Katoh, R.; Furube, A.; Tamaki, Y.; Murai, M.; Hara, K.; Murata, S.; Arakawa, H.; Tachiya, M. J. Phys. Chem. B 2004, 108, 3817.

(21) Delgass, W. N.; Haller, G. L.; Kellerman, R.; Lunsford, J. H. Spectroscopy in Heterogeneous Catalysis; Academic: New York, 1966.

(22) Rosencwaig, A.; Gersho, A. J. Appl. Phys. 1976, 47, 64.

(23) Tam, A. C. Rev. Mod. Phys. 1986, 58, 381.

(24) Toyoda, T.; Kawano, H.; Shen, Q.; Kotera, A.; Ohmori, M. Jpn. J. Appl. Phys. 2000, 39, 3160.

(25) Toyoda, T.; Taira, T.; Shen, Q.; Ohmori, M. Jpn. J. Appl. Phys. 2001, 40, 3587.

(26) Nosaka, Y.; Igarashi, R.; Miyama, H. Anal. Chem. 1985, 57, 92. 
(27) Murakami, N.; Mahaney, O. O. P.; Torimoto, T.; Ohtani, B. Chem. Phys. Lett. 2006, 426, 204.

(28) Highfield, J. G.; Grätzel, M. J. Phys. Chem. 1988, 92, 464.

(29) Iwasaki, T.; Oda, S.; Sawada, T.; Honda, K. J. Phys. Chem. 1980, 84, 2800.

(30) Shultz, A. N.; Jang, W. J.; Hetherington, W. M., III; Baer, D. R.; Wang, L.; Engelhard, M. H. Surf. Sci. 1995, 339, 114.

(31) Toyoda, T.; Hayashi, M.; Shen, Q. Jpn. J. Appl. Phys. 2003, 42, 3036.

(32) Boonstra, A. H.; Mutsaers, C. A. H. A. J. Phys. Chem. 1975, 79, 1940.

(33) Munuera, G.; Gonzalez-Elipe, A. R.; Fernadez, A.; Malet, P.; Espinos, J. P. J. Chem. Soc., Faraday Trans. 1 1989, 85, 1279.

(34) Ohno, T.; Masaki, Y.; Hirayama, S.; Matsumura, M. J. Catal. 2001, 204, 163 .

(35) Li, X.; Chen, C.; Zhao, J. Langmuir 2001, 17, 4118.

(36) Kormann, C.; Bahnemann, D. W.; Hoffmann, M. Environ. Sci. Technol. 1988, 22, 798.

(37) Nakamura, R.; Imanishi, A.; Murakoshi, K.; Nakato, Y. J. Am. Chem. Soc. 2003, 125, 7443.

(38) Jensen, H.; Soloviev, A.; Li, Z.; Sogaard, E. G. Appl. Surf. Sci. 2005, 246, 239.
(39) Nakaoka, Y.; Nosaka, Y. J. Photochem. Photobiol., A 1997, 110, 299.

(40) Hirakawa, T.; Nakaoka, Y.; Nishino, J.; Nosaka, Y. J. Phys. Chem. B 1999, 103, 4399 .

(41) Hirakawa, T.; Kominami, H.; Ohtani, B.; Nosaka, Y. J. Phys. Chem. B 2001, 105, 6993.

(42) Nosaka, A.; Fujiwara, T.; Yagi, H.; Akutsu, H.; Nosaka, Y. J. Phys. Chem. B 2004, 108, 9121.

(43) Nosaka, A. Y.; Nishino, J.; Fujiwara, T.; Ikegami, T.; Yagi, H.; Akutsu, H.; Nosaka, Y. J. Phys. Chem. B 2006, 110, 8380.

(44) Ohtani, B.; Zhang, S.-W.; Nishimoto, S.-i.; Kagiya, T. J. Chem. Soc., Faraday Trans. 1992, 88, 1049.

(45) Murakami, N.; Abe, R.; Mahaney, O. O. P.; Torimoto, T.; Ohtani, B. Stud. Surf. Sci. Catal. 2007, 172, 429.

(46) Bilmes, S. A.; Mandelbaum, P.; Alvarez, F.; Victoria, N. M. J. Phys. Chem. B 2000, 104, 9851 .

(47) Wang, L. Q.; Baer, D. R.; Engelhard, M. H.; Shultz, A. N. Surf. Sci. 1995, 344, 237

(48) Wang, L. Q.; Ferris, K. F.; Skiba, P. X.; Shultz, A. N.; Baer, D. R.; Engelhard, M. H. Surf. Sci. 1999, 440, 60. 